\title{
Metastatic Colorectal Mucinous Adenocarcinoma
}

National Cancer Institute

\section{Source}

National Cancer Institute. Metastatic Colorectal Mucinous Adenocarcinoma. NCI

Thesaurus. Code C162273.

Colorectal mucinous adenocarcinoma that has spread from the original site of growth to other anatomic sites. 